Heywood, M., Moutafsis, D. and Ogden, R. (2016) 'Embodied carbon efficient industrial buildings with optimized long span sandwich panels'. Interaction between Theory and Practice in Civil Engineering and Construction. European and Mediterranean Structural Engineering and Construction Conference, Istanbul, Turkey: ISEC Press. pp. 161-166.

DOI: https://doi.org/10.14455/ISEC.res.2016.87

This document is the Version of Record.

License: https://creativecommons.org/licenses/by-nc-nd/4.0

Available from RADAR: https://radar.brookes.ac.uk/radar/items/baf7cdd3-b673-4cdb-add0-2fed5bbcdee0/1/

Copyright $(\subseteq$ and Moral Rights are retained by the author(s) and/ or other copyright owners unless otherwise waved in a license stated or linked to above. A copy can be downloaded for personal non-commercial research or study, without prior permission or charge. This item cannot be reproduced or quoted extensively from without first obtaining permission in writing from the copyright holder(s). The content must not be changed in any way or sold commercially in any format or medium without the formal permission of the copyright holders.

This article may not be reproduced in any form or by any means electronic or mechanical, including photocopying, recording or any information storage and retrieval system now known or to be invented, without written permission from the Publisher, unless available in open access. 


\title{
EMBODIED CARBON EFFICIENT INDUSTRIAL BUILDINGS WITH OPTIMIZED LONG SPAN SANDWICH PANELS
}

\author{
MARTIN D. HEYWOOD, DIMITRIOS MOUTAFTSIS, and RAYMOND G. OGDEN
}

Faculty of Technology, Design and Environment, Oxford Brookes University, Oxford, UK

\begin{abstract}
A series of studies have been undertaken to quantify potential steelwork and embodied carbon savings in single-storey industrial buildings with long span sandwich panel roof cladding. It was found that trussed-roof frames with north lights offer the greatest potential steelwork saving $(38 \%-60 \%)$ against traditional portal frame construction when used with long span panels. However, in order to achieve the necessary span between adjacent frames, the structural performance of the sandwich panels needed to be improved. A subsequent study was undertaken to develop revised specifications for long span roof sandwich panels to increase their spanning capability, while minimizing the increase in embodied carbon. The mechanical resistance of the panels was evaluated using a combination of theoretical analysis and structural testing and a Pareto-optimal set of solutions was found. Finally, the optimized structure-envelope assembly was reviewed holistically in terms of its embodied carbon. The results showed that savings of up to $7.3 \%$ may be achieved for the frame when compared against traditional portal frame construction.
\end{abstract}

Keywords: Pareto-optimization, Structural testing, Cladding, Steel structures, North lights, Steelwork reduction.

\section{INTRODUCTION}

In Europe, buildings are responsible for $40 \%$ of energy consumption and are therefore at the core of efforts to meet climate change targets set by the EU and its member states. In an attempt to reduce the energy and $\mathrm{CO}_{2}$ associated with operating buildings, regulations have demanded ever increasing insulation thicknesses within the building envelope. This increase in the amount of insulation material has been resulting in higher levels of embodied carbon (i.e., the lifecycle greenhouse gas emissions occurring during manufacture and transport of construction materials and components, construction processes and building end-of-life aspects). In the case of composite insulated (sandwich) panels, where the strength of the panel relies on the composite action between the insulation core and bonded metal faces, the increased insulation thickness has also improved the panel's stiffness and bending resistance, theoretically allowing the panels to span further. This presents an opportunity to make greater structural use of the envelope, permitting the removal of some structural elements and reducing the overall level of embodied carbon within the building. 
Moutaftsis et al. (2015a) have determined the structural forms that are best able to utilize the structural capability of sandwich panels and examined the corresponding potential steelwork savings. Their study concluded that the greatest potential benefit arises from the use of long span envelope systems. Moutaftsis et al. (2015b) extended this analysis by reviewing the structure-envelope options in terms of their embodied carbon. A reduction in the embodied carbon associated with the structural frame was demonstrated in all schemes considered, but in order to maximize these savings, the sandwich panels were required to span over $8.0 \mathrm{~m}$ (for the medium and large buildings), beyond their current spanning capability.

The present study was undertaken to extend the previous research and identify improved specifications for long span roof sandwich panels with steel faces and a polyisocyanurate (PIR) core capable of spanning the optimum spacing between frames. Crucially, while it was necessary to improve the bending resistance and stiffness of the panels, it was also important to limit the increase in the panels' embodied carbon to ensure that savings in the embodied carbon of the frame were not offset by increased embodied carbon in the envelope. The focus of the present study was on single-story industrial buildings.

\section{METHODOLOGY}

Three generic building sizes were chosen as representative of modern single-storey industrial buildings and these are presented in Table 1. For each building size, a base scheme was defined for the structural frame to reflect current construction practice in the UK, together with a series of re-engineered structural frame schemes designed to exploit the structural capability of the cladding. The frames were designed by elastic analysis using the structural Eurocodes for an assumed location of Oxford, UK. This initial study took no account of the spanning capability of the sandwich panels.

The mechanical resistance of typical roof sandwich panels was then evaluated using a combination of theoretical analysis and a structural testing program. This led to the optimization study during which adjustments were made to the mechanical and geometrical properties of the panels to improve their bending resistance in order to achieve the desired spacing between structural frames, while minimizing any increase in embodied carbon. A Pareto-optimal set of solutions was found and single solutions were selected for the required load capacities. This element of the study followed a similar methodology to research by Kurpiela and Lange (2013). Finally, the structureenvelope assemblies were reviewed holistically in terms of their embodied carbon, using a 'Cradle-to-gate' approach and data by Jones and Hammond (2008).

\section{BUILDING STRUCTURE}

Four structural frame options were studied as shown in Table 2. The first scheme represents the current practice in the UK for single-storey industrial buildings, while the others are re-engineered to favour long-span cladding systems. A duo-pitch portal frame without purlin, a re-oriented portal frame and a north light truss are shown in Figure 1. For each scheme, the optimum frame spacing and the percentage reduction of steelwork weight (referred to as "steelwork reduction" and including the primary frame, 
bracing and secondary members) against the base case for the same frame spacing distance are presented in Table 2.

Table 1. Generic industrial building dimensions.

\begin{tabular}{cccccc}
\hline Building size & Width & Length & Height to eaves & Area & Roof pitch \\
\hline & $\mathrm{m}$ & $\mathrm{m}$ & $\mathrm{m}$ & $\mathrm{m}^{2}$ & degrees \\
\hline Small & 25 & 40 & 4 & 1,000 & 6 \\
Medium & 50 & 80 & 6 & 4,000 & 6 \\
Large & 80 & 125 & 6 & 10,000 & 6 \\
\hline
\end{tabular}

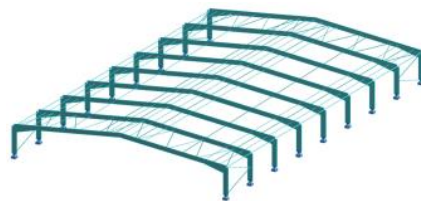

(a)

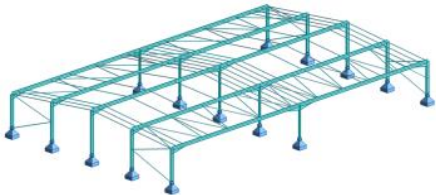

(b)

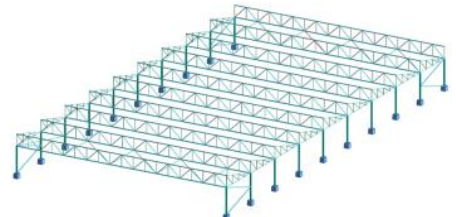

(c)

Figure 1. (a) Duo-pitch portal frames without purlins (b) Re-oriented portal frames (c) Truss roof with north lights.

\section{OPTIMIZATION OF SANDWICH PANELS FOR LONG SPAN ROOFS}

The study described above suggested that trussed roof frames with north lights provide the greatest potential for steelwork reduction for an optimum frame spacing of $6.67 \mathrm{~m}$ for small buildings and $8.00 \mathrm{~m}$ for medium and large buildings. As typical roof sandwich panels available today can already span $6.67 \mathrm{~m}$, the focus of the subsequent study was the re-engineering of the panels to achieve the $8.0 \mathrm{~m}$ span required for the medium and large buildings.

\subsection{Structural Testing}

The structural testing program was devised to determine (a) the effect of PIR core density on its mechanical properties and (b) the compressive resistance of fully and lightly profiled steel sheets with varying geometries. All tests were undertaken according to EN 14509:2013 (CEN, 2013). The properties determined included: Density $\left(\rho_{C}\right)$; Shear modulus $\left(G_{C}\right)$ and strength $\left(f_{C v}\right)$; Compression modulus $\left(E_{C c}\right)$ and strength $\left(f_{C c}\right)$; Tension modulus $\left(E_{C t}\right)$ and strength $\left(f_{C t}\right)$; Poisson ratio $(v)$. Linear relationships between core density and the mechanical properties were determined based on statistical analysis. The test results to determine the compressive resistance of the steel sheets were compared against those obtained from existing analytical methods.

The study showed that, for the given slenderness ratios, the fully profiled sheets may be regarded as fully effective with the compressive resistance of the sheets equal to the yield strength. For the lightly profiled sheets, the model of Pokharel and Mahendran (2003) was found to give the best results when the depth was in excess of $3 \mathrm{~mm}$, while the formulas of Stamm and Witte (1974) were ideal for rib depth below $3 \mathrm{~mm}$. These methods were therefore chosen for the optimization model. 
Table 2. Steelwork reduction against base case and optimum frame spacing.

\begin{tabular}{ccc}
\hline Scheme & Steelwork reduction & Optimum frame spacing \\
\hline $\begin{array}{c}\text { Duo-pitch portal frame } \\
\text { with purlins }\end{array}$ & N/A (base case) & $\begin{array}{c}\text { Small: } 6.67 \mathrm{~m} \\
\text { Medium: } 8.00 \mathrm{~m}-13.3 \mathrm{~m} \\
\text { Large: } 10.00 \mathrm{~m}-13.3 \mathrm{~m}\end{array}$ \\
\hline \multirow{2}{*}{$\begin{array}{c}\text { Duo-pitch portal frame } \\
\text { without purlins }\end{array}$} & Small: $6 \%$ & Small: $6.67 \mathrm{~m}$ \\
& Ledium: $1 \%-13 \%$ & $\begin{array}{c}\text { Medium: } 8.00 \mathrm{~m}-13.34 \mathrm{~m} \\
\text { Large: } 4 \%-19 \%\end{array}$ \\
\hline \multirow{3}{*}{ Re-oriented portal frames $10.00 \mathrm{~m}-13.33 \mathrm{~m}$} \\
\hline \multirow{2}{*}{ Truss roof with north } \\
lights & Small: $13 \%$ & Small: $6.25 \mathrm{~m}$ \\
& Large: $34 \%-42 \%$ & Large: $10.00 \mathrm{~m}-13.3 \mathrm{~m}$ \\
& Small: $20 \%-38 \%$ & Small: $6.67 \mathrm{~m}$ \\
& Medium: $46 \%-53 \%$ & Medium: $6.67 \mathrm{~m}-10.00 \mathrm{~m}$ \\
& Large: $49 \%-55 \%$ & Large: $8.00 \mathrm{~m}$ \\
\hline
\end{tabular}

\subsection{Optimization of Roof Sandwich Panels with Fully Profiled Faces}

The problem was defined as maximizing the resistance of the panel while minimizing the embodied carbon. When the required resistance is known for the given span, a single optimal solution can be found. The problem may be described by Eq. (1):

$$
\text { minimize } f(x)=\left[f_{1}(x), f_{2}(x)^{T}\right]
$$

Where $f_{1}(x)=1 / q, q$ being the maximum resistance and $f_{2}(x)=k_{P I R} W_{P I R}+k_{\text {Steel }} W_{\text {Steel }}$ is the embodied carbon function using the carbon coefficients of PIR $\left(k_{P I R}\right)$ and galvanized steel $\left(k_{\text {Steel }}\right)$ and $\mathrm{W}_{\text {PIR }}$ and $\mathrm{W}_{\text {Steel }}$ refer to the weight of PIR and steel respectively. The results are expressed in $\mathrm{kgCO}_{2} \mathrm{e} / \mathrm{m}^{2}$.

The variable vector $x$ includes all the geometrical and mechanical properties which influence the strength and stiffness behavior of a sandwich panel with one face fully profiled and one face lightly profiled. Since relationships between the core density and its mechanical properties were earlier established, the variable vector can be reduced to:

$$
x=\left[D, d_{1}, h_{1}, h_{2}, b_{1}, b_{2}, \rho_{C}, f_{y 1}, f_{y 2}, t_{F 1}, t_{F 2}\right]
$$

Where $D$ is the depth of the panel excluding the height of the full profile $d_{l}$ at the outer face; $h_{i}$ is the height and $b_{i}$ the width of the light profiles at each face; $t_{f, i}$ is the thickness and $f_{y, i}$ the yield strength of each steel face; subscripts 1 and 2 refer to the outer and inner faces of the panel respectively.

The constraints were associated with the design checks in terms of strength and stiffness according to EN 14509:2013 (CEN 2013). Temperature effects were also taken into account, considering medium-color for the outer face of the panel. The following ranges of properties were adopted for the study:

$$
\begin{aligned}
100 \mathrm{~mm} \leq & D \leq 150 \mathrm{~mm} ; 31.3 \mathrm{~mm} \leq d_{1} \leq 61.3 \mathrm{~mm} ; h_{1}=h_{2}=3 \mathrm{~mm}, 23.8 \mathrm{~mm} \leq b_{2} \leq 33.8 \mathrm{~mm} ; \\
& 0.45 \mathrm{~mm} \leq t_{F 1} \leq 0.75 \mathrm{~mm} ; 0.35 \mathrm{~mm} \leq t_{F 2} \leq 0.65 \mathrm{~mm} ; f_{y 1}=f_{y 2}=350 \mathrm{~N} / \mathrm{mm}^{2}
\end{aligned}
$$

The solutions are shown in Figure 2 and include optimal and non-optimal solutions. The lower bound series is the Pareto-optimal solution. For desired characteristic loads of $+0.60 \mathrm{kN} / \mathrm{m}^{2}$ in pressure and $-0.90 \mathrm{kN} / \mathrm{m}^{2}$ in suction for the assumed load conditions 
in the study, a single optimal solution can be determined on the Pareto-front. This gives a panel specification with the variables and embodied carbon shown in Eq. (1). The reengineered panel has $13.9 \%$ more embodied carbon compared to the currently available panels with the same thermal performance $\left(\mathrm{U}-\mathrm{value}=0.15 \mathrm{~W} / \mathrm{m}^{2} \mathrm{~K}\right)$.

$$
\begin{aligned}
& x=\left[D=150 \mathrm{~mm}, d_{1}=61.3 \mathrm{~mm}, h_{1}=, h_{2}=3 \mathrm{~mm}, b_{2}=23.8 \mathrm{~mm}, \rho_{C}=38 \mathrm{~kg} / \mathrm{m}^{3}\right. \\
& \left.f_{y 1}=f_{y 2}=350 \mathrm{~N} / \mathrm{mm}^{2}, t_{F 1}=0.44 \mathrm{~mm}, t_{F 2}=0.34 \mathrm{~mm}\right] ; f_{2}(x)=38.21 \mathrm{CO}_{2} \mathrm{e} / \mathrm{m}^{2}
\end{aligned}
$$

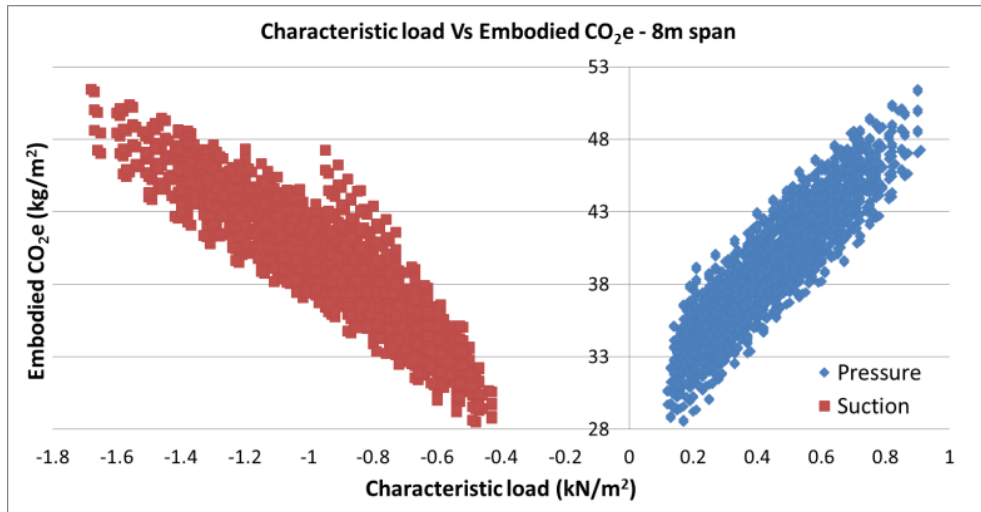

Figure 2. Solutions for $8 \mathrm{~m}$ single-span sandwich panels, medium-color group.

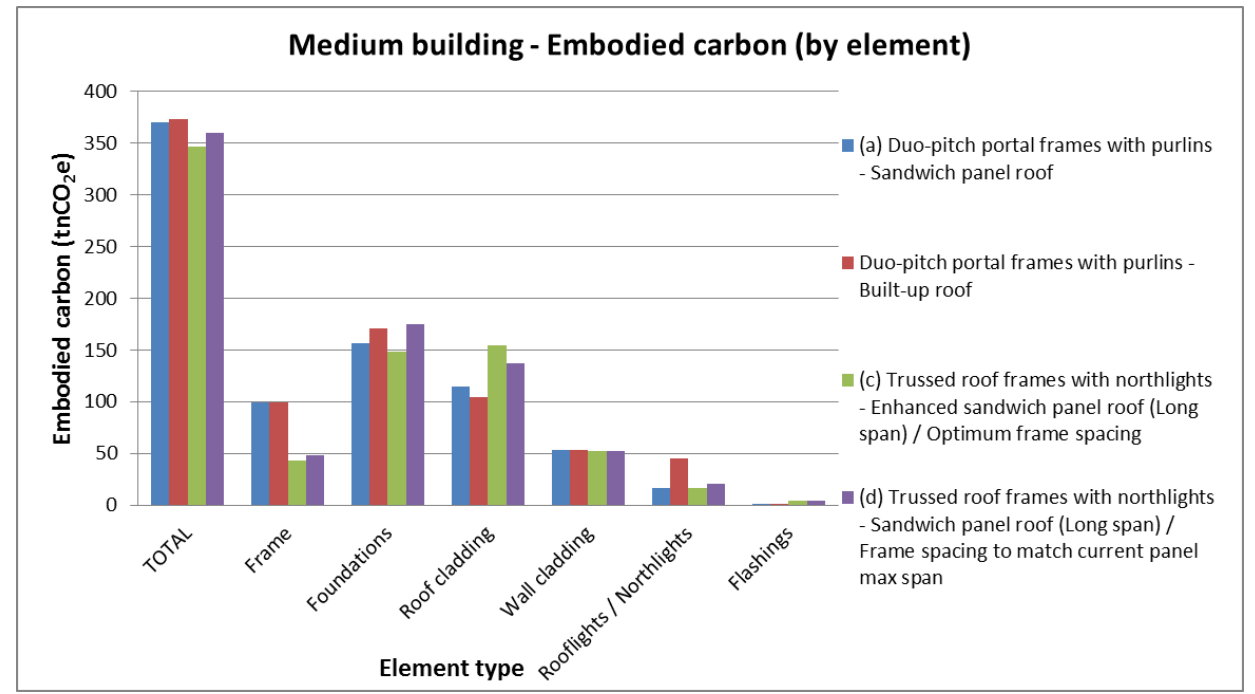

Figure 3. Embodied carbon for various schemes (medium-sized building).

\section{EMBODIED CARBON OF STRUCTURE-ENVELOPE ASSEMBLIES}

An embodied carbon review was undertaken for the combined structure and envelope using a 'Cradle-to-gate' approach and data by Jones and Hammond (2008). The schemes selected for comparison were traditional portal frames with purlins using (a) sandwich panels, (b) built-up twin skin metal cladding and trussed-roof frames with 
north lights using long span roof sandwich panels at (c) optimum frame spacing comprising the enhanced panels and (d) with frame spacing at the maximum span possible using current technology. Sandwich panel wall cladding systems were selected for all schemes, together with appropriate specifications for rooflights / north lights glazing and flashings. Figure 3 shows the results for the medium-sized building.

It is apparent that scheme (c) gives a reduction of $6.5 \%$ against scheme (a) and $7.3 \%$ against scheme (b) in terms of total embodied carbon. Schemes (c) and (d) have a much lesser impact in terms of emission associated with the frame due to the reduced steelwork weight, but their impact is higher for the roof cladding due to the enhanced sandwich panel specifications and increased envelope area. There is an overall higher superstructure weight for schemes (b) (due to the heavier built-up cladding) and (d) (due to non-optimum frame spacing). Finally, the study showed that the selection of rooflight / north light glazing system has a considerable impact on the total embodied carbon of the structure. Similar results were also found for the large building size, while the differences were only very small for the small building.

\section{CONCLUSIONS}

This study has demonstrated that a significant saving in embodied carbon is possible by exploiting the spanning capability of modern sandwich panel roof cladding to reduce the weight of the structural frame. However, in order to take full advantage of this potential saving, it is necessary to make minor changes to the panels to optimize their performance. An enhanced sandwich panel specification has been presented that meets this requirement.

\section{Acknowledgments}

The authors would like to thank the Engineering and Physical Sciences Research Council (EPSRC) and TATA Steel Colors for the financially sponsoring the research project.

\section{References}

European Committee for Standardization (CEN), EN 14509:2013: Self-supporting double skin metal faced insulating panels - Factory made products - Specifications, Brussels, 2013.

Jones C and Hammond G (2008) Inventory of Carbon \& Energy (ICE) (Version 1.6a). Bath: Sustainable Energy Research Team (SERT), University of Bath.

Kurpiela A., Lange J., Optimierung von Sandwichwandbauteilen (Optimisation of wall sandwich panels), Stahlbau, 82(11), p. 843-850, 2013.

Moutaftsis, D., Heywood, M. D., Ogden, R. G. Improved Structural Efficiency in Steel Single Storey Buildings using Sandwich Panels, Proceedings of the 8th International Conference on Advances in Steel Structure, Lisbon, Portugal, 21-24 July, 2015a.

Moutaftsis, D., Resalati, S., Heywood, M. D., Ogden, R. G., Optimised Low and Operational carbon solutions for single storey industrial buildings, Proceedings of the Eighth International Structural Engineering and Construction Conference: Sustainable Solutions in Structural Engineering and Construction, Sydney, Australia, 23-28 November, $2015 \mathrm{~b}$.

Pokharel N. and Mahendran M., Experimental investigation and design of sandwich panels subject to local buckling effects, Journal of Constructional Steel Research, Volume 59, Issue 12, p. 1533-1552, 2003.

Stamm, K. and Witte, H., Sandwichkonstructionen \pm Berechnung, Fertigung, Ausfuhrung (Sandwich Construction - Calculation, Manufacture and Use), Springer-Verlag, Wien and New York, 1974. 